\title{
OS USOS DE AGROTÓXICOS “CONTRABANDEADOS” NA FRONTEIRA BRASIL-PARAGUAI E AS EXPERIÊNCIAS DOS PEQUENOS PRODUTORES RURAIS NO PARANÁ (1960-2018)
}

\author{
THE USES OF “SMUGGLED” PESTICIDES ON THE BRAZIL- \\ PARAGUAY BORDER AND THE EXPERIENCES OF SMALL RURAL \\ PRODUCERS ON THE PARANÁ (1960-2018)
}

Cíntia Fiorotti Lima ${ }^{1}$

\begin{abstract}
RESUMO: O objetivo da pesquisa apresentada foi analisar: as pressões sofridas pelos trabalhadores e/ou pequenos produtores rurais que utilizam em seus cultivos agrícolas agrotóxicos "contrabandeados" do Paraguai para o Brasil; e, por outro lado, as alternativas desenvolvidas por aqueles que resistem ao envolvimento neste circuito para conseguirem permanecer com o trabalho no campo, por meio da produção orgânica ou agroecológica. Para tanto, são trazidas algumas informações sobre a circulação de agrotóxico nos limites territoriais entre os Departamentos de Canindeyu e Alto Paraná no Paraguai e a região Oeste do Paraná no Brasil. Esses dados foram levantados a partir de produções bibliográficas sobre o tema; matérias veiculadas em jornais locais; sentenças judiciais; entrevistas com produtores rurais e com agentes do Estado responsáveis pela fiscalização e/ou apreensões. A pesquisa filia-se a área de conhecimento da História Social.
\end{abstract}

PALAVRAS-CHAVE: Trabalhadores; Agrotóxicos; Fronteiras; Pequenos Produtores rurais.

\footnotetext{
* Este texto é resultado do trabalho realizado durante o pós-doutorado em História no PPGH da UNIOESTE, mas que encontrava-se associado a um projeto mais amplo intitulado "Relações de poder e os sujeitos consumidores de agrotóxicos", vinculado ao Grupo de Pesquisa "Fronteiras, Estados e Relações Sociais", tendo ainda, contribuições de um projeto de pesquisa denominado "Contrabando de agrotóxicos na fronteira Brasil-Paraguai" apresentado na UNILA quando era professora visitante no curso de licenciatura em História. A pesquisa chegou a ser anunciada como contemplada com bolsa de estudos para pós-doutorado, mas não chegou a ser efetivada, pois na leitura do PPGH, o CNPQ não permitia que professores da educação básica recebessem bolsa de pós-doutorado. Assim, a pesquisa foi realizada sem financiamento, conciliada posteriormente com o trabalho de professora visitante e, partes, durante o período de licença maternidade.

${ }^{1}$ Doutorado em História Social pela UFU, mestrado e graduação em História pela UNIOESTE. Professora do quadro próprio da SEED/PR e colaboradora na UNIOESTE. Pesquisadora vinculada ao LAFRONT.
} 


\begin{abstract}
The purpose of this text is to discuss what are the pressures suffered by workers and/or small rural producers who use in their agricultural crops "smuggled" from Paraguay to Brazil. Together, we analyze what are the alternatives found by those who resist involvement in this circuit in order to continue with the field work, through organic or agroecological production. Some information is provided on the circulation of pesticides in the territorial limits between the departments of Canindeyu and Alto Paraná, in Paraguay, and the western region of Paraná, in Brazil. These data were collected from: bibliographic productions on the topic; articles published in local newspapers; court sentences; interviews with rural producers and State agents responsible for inspections and / or seizures. The research is affiliated to the area of knowledge of Social History.
\end{abstract}

KEYWORDS: Workers; Smuggling; Pesticides; Borders; small rural producers.

\title{
Introdução
}

O trânsito de pessoas e o comércio de mercadorias em torno da produção agrícola entre a fronteira Brasil-Paraguai-Argentina não é algo recente na região Oeste do Paraná. Entre as cidades brasileiras Guaíra e Mundo Novo, na fronteira com a municipalidade de Salto del Guairá/Paraguai, identificamos a circulação de trabalhadores e a comercialização de produtos voltados para o abastecimento de bens de consumo oriundos da produção agrícola nesta região ao menos desde 1940 (FIOROTTI, 2015). Nestes casos, os trabalhadores possuíam certa autonomia na organização da produção e/ou distribuição resultante de sua produção rural, disposta em pequenas propriedades direcionadas para subsistência e comercialização dos excedentes.

Durante a "expansão da fronteira agrícola" entre as décadas de 1960 e 1980, uma parcela importante dos cultivos passaram a ser aparelhados com a produção extensiva no campo combinada à monocultura e, dependendo do cultivo, ao uso de maquinários e à sistemática aplicação de agrotóxicos. Nesse momento, identificamos um arranjo diferente de algumas das formas de trabalho em áreas rurais na região de fronteira Brasil/Paraguai. Por exemplo, em uma pesquisa realizada nos autos-criminais catalogados como "contrabando" alocados no Fundo Documental do Fórum da Comarca de Toledo-PR, emergiu como prática comum aos produtores rurais de café o 
transporte não regulamentado do produto para o Paraguai. $\mathrm{Na}$ análise dos testemunhos de trabalhadores presos e dos agentes do Estado envolvidos nas fiscalizações e punições, constatou-se que os trabalhadores eram mobilizados como força de trabalho para o transporte nas barrancas dos rios, batedores de estrada, bandeirinhas e motoristas de caminhão.

A circulação transfronteiriça de produtos agrícolas na região é observada em outros estudos. Alfredo da Mota Menezes, por exemplo, indicou uma alta circulação do trânsito de soja entre a fronteira brasileira do Mato Grosso do Sul e o Paraguai na década de 1970. A quantidade de soja produzida pelo Paraguai era superior à sua extensão territorial possível de produção à época (MENEZES, 1987). Conforme o autor, a facilidade para conseguir a documentação comprovando a produção agrícola no Paraguai estava combinada à compra de muitas terras naquele país por brasileiros. Essa forma de organização contribuía para que muitos desses proprietários brasileiros de terras no Paraguai e, vice-versa, lidassem com as diferenças monetárias e tributarias entre os dois países para se beneficiarem dessas, aproveitando-se das oscilações econômicas e políticas de cada período (FIOROTTI, 2015). Da mesma forma, o consumo de produtos, como agrotóxicos utilizados nas lavouras, também ocorria na fronteira sem as devidas regulamentações.

Durante a pesquisa realizada nos autos criminais das Comarcas de Toledo (1954-1980) e de Foz do Iguaçu (1980-1990), não observamos o registro de casos de apreensões de trabalhadores envolvidos no contrabando de soja e de agrotóxicos. Esse silêncio também foi observado na pesquisa aos jornais Ilha Grande na década de 1980 e ao jornal O Paranazão na década de 1990, ambos com circulação entre Guaíra, Mundo Novo e Salto del Guairá. Nos campos reservados para notícias policiais, havia reportagens sobre as apreensões de contrabando e/ou descaminho de café, eletrônicos, bebidas cigarros, armamento, munições, drogas etc. No entanto, as entrevistas realizadas com empresários proprietários de agropecuárias e loja de ferramentas em Salto del Guairá na década de 1970, apontam para a existência de vendas de agrotóxicos, sementes e adubos para produtores rurais com terras no Brasil ou 
em ambos os países para serem utilizadas na produção de soja e milho na região Oeste do Paraná. ${ }^{2}$

Entre os anos de 2013 a maio de 2017, os postos da Receita Federal de Foz do Iguaçu e de Guaíra registraram 288 apreensões de agrotóxicos, sinalizando um aumento destas apreensões a partir de 2016.

Tabela 01 - Apreensões de agrotóxicos por quantidade de volume pela receita federal de Foz do Iguaçu e Guaíra

\begin{tabular}{|c|c|c|}
\hline Ano da apreensão & Número de apreensões & Valor estipulado em dólares \\
\hline 2013 & 45 & $258.981,28$ \\
\hline 2014 & 46 & $86.704,23$ \\
\hline 2015 & 58 & $104.803,00$ \\
\hline 2016 & 82 & $61.649,90$ \\
\hline 2017 (janeiro a maio) & 57 & $131.564,25$ \\
\hline TOTAIS & 288 & $531.303,16$ \\
\hline
\end{tabular}

Fonte: Dados da Receita Federal, organizados pelo LAFRONT (2017).

Para compararmos os dados da Tabela 01, traremos informações sobre duas mercadorias com maiores números de apreensões, a partir de uma amostragem fornecida e identificada pela Receita Federal como "apreensões de mercadorias com valores totais em dólares pela Receita Federal de Foz do Iguaçu, 2013 a 2017”, os cigarros e os eletrônicos. Os primeiros chegaram a totalizar aproximadamente 206 milhões de dólares, enquanto os segundos mais de 60 milhões de dólares apreendidos. Embora os agrotóxicos contrabandeados sejam expressos em quantidade de apreensões e os dados sobre o cigarro e os eletrônicos em valor monetário/dólar, num recorte espacial apenas da Receita Federal de Foz do Iguaçu, observa-se que as apreensões de agrotóxicos foram muito reduzidas ao serem comparadas com as duas demais mercadorias apresentadas.

\footnotetext{
${ }^{2}$ Edu, 50 anos, nacionalidade paraguaia, residente em Salto del Guairá e Maria Cleuza, 73 anos, nacionalidade brasileira e residente na mesma cidade e em Mundo Novo. Entrevista gravada em outubro de 2013 em Salto del Guairá.
} 
Por mais que a quantidade de apreensões de agrotóxicos demonstradas trouxessem somente aquilo que a Receita Federal conseguia fiscalizar e notificar, esses dados vão ao encontro do levantamento de informações sobre as operações de fiscalização na fronteira voltadas para o controle da entrada irregular ou ilegal de agrotóxicos. Isso, quando comparado às várias ações/operações policiais destinadas ao controle de cigarros, eletrônicos, drogas e armas vindas do Paraguai para o Brasil. Contudo, é necessário explicitar que a quantidade de apreensões realizadas no país era insignificante quando comparada com outras mercadorias apreendidas até o ano de 2017. De fato, o combate à importação irregular de agrotóxicos ganhou maior destaque nas operações de controle e nas mídias posteriormente, quando se inicia uma política sistemática de ampliação do número de moléculas permitidas no território brasileiro. Período que coincide com a significativa representação política da bancada ruralista nos resultados das eleições de 2018.

O combate à importação irregular de agrotóxicos é proporcional ao registro de novas substâncias atribuídas pela legislação brasileira aos Ministério da Agricultura, Pecuária e Abastecimento - MAPA, Ministério do Meio Ambiente - MMA e Ministério da Saúde - MS. Não suficiente, destaca-se o fato dos Estados também possuírem responsabilidades na regulamentação da aplicação, comércio, consumo e armazenamento dos agrotóxicos. Por isso, pode haver variações nas regulamentações de acordo com os interesses de cada região. Como exemplo, temos o produto benzoato de emamectina.

Atualmente, um dos produtos de maior circulação nesse comércio ilegal é o benzoato de emamectina, utilizado no combate à Helicoverpa armígera, espécie de lagarta comum nas lavouras de soja brasileiras. O princípio ativo teve aprovação provisória e emergencial para seis estados até julho de 2019 e aprovação definitivo para apenas uma marca comercial no Brasil, na concentração máxima de 5\%. No Paraguai, o teto estabelecido para a concentração deste princípio ativo de defensivos agrícolas é de $10 \%$. Porém, as substâncias contrabandeadas do país vizinho chegam a ter índice de concentração $600 \%$ superior ao percentual permitido no Brasil. (IDESF, 2019, p. 9-10.) 
Os dados apresentados pelo Instituto de Desenvolvimento Econômico e Social de Fronteiras (IDESF), na publicação, "O contrabando de defensivos agrícolas no Brasil”, 2018-2019, indicou que a quantidade registrada de importações dessa substância pelo Paraguai excederia a necessidade de abastecimento para os usos nas áreas produtivas de soja do país. Conforme a fonte citada, "em cinco anos, a diferença foi de 225\%, uma evolução que não reflete o crescimento da agricultura no país vizinho". (IDESF, 2019, p.15). Tais informações teriam sido organizadas a partir de matérias de jornais de circulação regionais e nacionais no Paraguai e no Brasil; operações independentes realizadas pela Polícia Federal e/ou em conjunto a outras instituições federais brasileiras; informações passadas pelo Sindicato Nacional da Indústria de Produtos para a Defesa Vegetal - SINDIVEG; Confederação da Agricultura e Pecuária do Brasil - CNA; Aduana do Paraguai, dentre outras fontes classificadas por eles como oficiais.

De modo geral, o IDESF apresenta logo no título da publicação citada sua escolha política sobre o tema. Como já alertaram alguns estudiosos, entre eles, Paulo Petersen (2015), coordenador executivo da AS-PTA Agricultura Familiar e Agroecologia, o termo "defensivo agrícola", expressa os esforços dos envolvidos no mercado da produção agrícola em atribuir o sentido de um produto necessário para defender as plantas de danos naturais e atender às demandas da quantidade de produção alimentícia a nível global. No Brasil, o Projeto de Lei (PL) 6.299/2002, entre outros aspectos, visou legitimar e mascarar os impactos do uso dos agrotóxicos na natureza e saúde, substituindo o termo "agrotóxicos" por "defensivo fitossanitário e produtos de controle ambiental". 3

\footnotetext{
${ }^{3}$ Ao final da publicação do IDESF, emerge o texto "Reflexões sobre o sistema jurídico em relação ao agroquímico "pirata", da autoria de Javert Ribeiro da Fonseca Neto. O conteúdo desse último, em acordo com informações já apresentada na publicação, discute sobre as punições para quem realizar ou utilizar "defensivos agrícolas contrabandeados". Além disso, propõe mudanças legislativas para controle e punição, prevendo penas mais duras que as já existentes. Isso vai ao encontro das atividades desenvolvidas pelo instituto, como o auxílio na elaboração de projetos de leis para deputados e senadores. Em 2019, o instituto teve participação em audiência pública no senado para debater o "contrabando de defensivos agrícolas", solicitada pela senadora Soraya Thronicke, representante do Estado do Mato Grosso
} 
As diferenças legislativas entre os índices permitidos e o uso de determinadas substâncias variam entre regiões, países e acordos internacionais que envolvem nações num mesmo bloco econômico e político. Como mencionado, no caso de produtos considerados de origem não regulamentada na importação e os adulterados, os estímulos facilmente visualizados estão na alta concentração das substâncias, nas inovações e na redução de custos das mercadorias. Contudo, outros elementos precisam ser analisados e problematizados. Neste sentido, o intuito da pesquisa realizada foi estudar os trabalhadores mobilizados nas diversas etapas de produção, distribuição e usos dos agrotóxicos. Assim como os aspectos culturais e sociais envolvendo os modos de vida dos pequenos produtores rurais que fazem uso e dos que resistem ao uso dos agrotóxicos.

As fontes utilizadas para esta pesquisa foram entrevistas com pequenos produtores rurais fossem ou não envolvidos com cultivos de orgânicos e/ou agroecológicos, com atravessadores de mercadorias não regulamentadas e/ou ilegais na fronteira Paraguai-Brasil, com agentes do Estado responsáveis pela fiscalização e/ou apreensões. Foram feitas aproximadamente 19 entrevistas. Destas, cerca de 17 entrevistas realizadas junto a alguns pesquisadores envolvidos no projeto "Relações de Poder e os sujeitos consumidores de agrotóxicos" do Laboratório de Pesquisa em Fronteiras, Estado e Relações Sociais - LAFRONT. A elaboração do roteiro prévio para as entrevistas buscou alguns eixos temáticos a serem abordados, onde se destacam: as trajetórias de vida; a busca pela permanência no campo e os modos de vida. Tais entrevistas ocorriam na casa dos pequenos proprietários rurais, começavam sendo gravadas e continuavam sem registro do áudio ao longo das caminhadas pelas áreas de cultivos. Sempre com a presença de mais de uma pessoa da família. O roteiro serviu como apoio, sendo foi priorizado a escuta e o tempo de fala dos sujeitos pesquisados, visando valorizar as experiências e interpretações possibilitadas pelo uso das fontes orais.

do Sul pelo Partido Social Liberal, presidente da Comissão de Agricultura do Senado e articulada à bancada ruralista. 
Também foram analisados encartes de divulgação das empresas produtoras de agrotóxicos evolvidas em exportações entre Paraguai e Brasil, sentenças judiciais e matérias sobre o tema veiculadas na impressa local e nacional. Estas fontes foram utilizadas para extrair informações e analisar o circuito do comércio de agrotóxicos não regulamentados e/ou ilegais na fronteira Paraguai-Brasil. Estes documentos foram problematizados, quanto aos seus silêncios e a luta de classes manifestos entre o Estado, grandes proprietários rurais e os trabalhadores envolvidos nessas relações sociais.

Origem, produção e venda dos agrotóxicos “contrabandeados"

Para apresentar a origem e produção dos agrotóxicos discutidos, traremos como exemplo a forma como a empresa Tangerina ${ }^{4}$ divulga sua produção e comercialização na América Latina. Em um encarte de divulgação do grupo empresarial Pinha (2018), esse se identifica como composto pelas empresas Laranja S.A., Tangerina, Tarumã, Manga e Aratiku. Conforme o pesquisador Luiz Rojas Villagra (2009) destaca em sua obra "Actores del agronegócio em Paraguay", entre os empresários do grupo Pinha estão os irmãos Jojó, Papá e Tom, todos de nacionalidade brasileira com vários anos de estabelecimento de negócios no Paraguai e no Brasil, tendo as duas primeiras empresas como as principais do grupo.

Entretanto, a pesquisa de ROJAS VILLAGRA (2009), considerou a Laranja, criada em 1993 e sediada em Ciudad del Este, como a principal representante da Monsanto no Paraguai e uma das maiores importadoras de insumos agrícolas no país. A Tangerina está vinculada a essa empresa. Em 2009, era responsável por cerca de $20 \%$ do mercado nacional, exportando para Bolívia, Argentina, Brasil, Colômbia e México, tendo sido acusada de

\footnotetext{
${ }^{4}$ Os nomes das empresas e grupos/corporações citadas foram substituídos por nomes de frutas. Também, os nomes de seus representantes por pseudônimos. Isso foi uma ação preventiva a futuras represálias ou ameaças de processo, situações estas já vivenciadas anteriormente pela autora. A substituição dos nomes por pseudônimos visou não comprometer os objetivos do texto.
} 
sonegação de impostos na Argentina e de poluição no Rio Chico e seus afluentes no Paraguai (ROJAS VILLAGRA, 2009).

Conforme a apresentação feita pela empresa, a Tangerina afirma ter mais de 28 anos no mercado de agroquímicos no Paraguai em 2018, possuindo uma fábrica para elaboração de agrotóxicos na Estância Las Violetas, localizada na cidade de Villeta no Paraguai, e uma oficina comercial com fábrica em Nanchang na China. Afirma importar matéria-prima para elaboração de fertilizantes, agroquímicos e pesticidas da China, com o grupo Bluberry com Longan. Indicam que na China, ocorrem acordos de produção com outras empresas locais. Também menciona ter um laboratório preventivo a contaminação cruzada e possuir mais de 90 ingredientes ativos, sendo os registros dos agroquímicos consolidados na Colômbia, México e Uruguai. A distribuição ocorre no Paraguai, na Bolívia e principalmente no Brasil.

No Brasil, essa empresa afirma possuir estrutura administrativa em Foz do Iguaçu-PR e em Ribeirão Preto - SP, além de equipes comerciais nas regiões sul, sudeste e centro-oeste. Conforme a divulgação da empresa, 52\% do mercado de "defensivos agrícolas" concentra-se na produção de soja no Brasil. Além disso, o material de divulgação da empresa apresenta mais dez produtos novos com registros a serem realizados entre dezembro de 2018 e o segundo trimestre de 2019 no Brasil. Já em abril de 2019, a empresa havia conseguido a liberação de metade deles, no mesmo pacote da liberação de mais 31 novos agrotóxicos pelo Ato No. 24 de 09 de abril de 2019, onde o ministério da agricultura realizava a defesa da liberação em favor ao combate do contrabando de agrotóxicos (CARMO, 2019; OLIVEIRA, 2020; MOREIRA, 2019).

Como observado, o processo de produção e circulação dos agrotóxicos envolve o trânsito de capitais, matérias primas, tecnologias e força de trabalho de diferentes localidades. As estratégias de fixação de suas plantas produtivas e comercialização são articuladas às aberturas políticas legislativas e aspectos econômicos, sociais e culturais dos países e regiões escolhidos. Como citado, os laboratórios de ponta para pesquisa e elaboração de moléculas encontram-se em um dos países de capitalismo central, a China, bem como parte das plantas 
produtivas para exploração do trabalho no sistema fabril. Enquanto, no Paraguai, os laboratórios realizam a reprodução dessas moléculas, concentrando-se poucas plantas produtivas. Como atrativo à expansão capitalista do setor, estão as liberdades políticas para exploração do trabalho e para possíveis contaminações e devastações ambientais decorrentes da produção de substâncias químicas que proporcionam danos à saúde e ao meio ambiente.

Conforme Adriana Dorfman e Carmen Janete Rekowski (2011), associam-se a isso a forma como trabalham as empresas transnacionais de agrotóxicos, como a Bayer, que vem atuando globalmente e pressionando a opinião pública e as legislações vigentes de diversos países, entre eles, os do América Latina, para liberação do uso de determinadas substâncias. Como reforçam as autoras, há a tentativa de subordinação de normas nacionais às demandas internacionais de commodities. Assim, "o contrabando, em seus aspectos geográficos, adéqua seus fluxos e fixos às demandas do mercado, às tecnologias disponíveis e a criminalização e/ou valorização de certos objetos por diferentes agentes". (DORFMAN; REKOWSKI, 2011: p. 02).

A princípio, o que chamamos popularmente de "contrabando" de agrotóxicos é identificado no meio jurídico como "importação irregular de agrotóxicos estrangeiros", como consta na Sentença Pública da Operação Quileros (deflagrada em 2012 e disponibilizada em agosto de 2018), que investigou o contrabando de agrotóxicos entre a fronteira do Rio Grande do Sul com o Uruguai. Enquanto dentro das normas jurídicas brasileiras que consideram crime a presença ou a alta concentração de algumas substâncias químicas, em outros países da América Latina, elas podem estar permitidas e legalizadas, como no caso de parte dos produtos oriundos do Uruguai.

A referida sentença ilumina para a existência de diversas vias para a entrada ilegal de agrotóxicos no Brasil. Na Operação Quileros, por exemplo, o contrabando estava articulado ao cadastro de empresas de produtos de limpezas, a falsificação de rótulos, selos e notas fiscais inautênticas. Entre os transportes, havia agrotóxicos em cargas de grãos ou de farelos de arroz que eram vendidos 
para posterior consumo após o transporte. Entre os destinos, estavam produtores no Mato Grosso do Sul.

O IDESF, ao analisar outras Operações da Polícia Federal em conjunto a outras instituições, mencionou que, em muitos casos, as apreensões realizadas ocorrem em situações em que os agrotóxicos "contrabandeados" se encontram "escondidos" entre produtos com documentação regulamentadas, em cargas de grãos, farinha de trigo, produtos de limpezas e adubos, por exemplo. Além disso, o instituto afirma haver falsificações, com a adição de produtos químicos diferentes da mercadoria pronta de origem contrabandeadas, antes dos mesmos serem destinados a demais regiões produtoras no Brasil.

Ainda, conforme informações trazidas pelo IDESF, uma das rotas do circuito teria como fornecedor de "substâncias químicas" a China, com entrada dos agrotóxicos pelos portos chilenos, importados pelo Paraguai, Bolívia e Uruguai, entrando posteriormente no Brasil por meio do "contrabando". Esses teriam sua importação adulterada, sendo os agrotóxicos ou suas matrizes de produção, registradas nos documentos de importação e exportação como outras substâncias ou mercadorias. Por exemplo, produtos de limpeza ou produtos químicos bases para diversos tipos de mercadorias industrializadas. Os trânsitos envolveriam desde vias fluviais, terrestres e aéreas. Entre as estratégias realizadas para facilitar as importações, em uma das matérias citadas no texto, o Panamá, emerge como local de origem da "matéria-prima".

Por meio das leituras de alguns jornais brasileiros e paraguaios com circulação em suas fronteiras e das informações levantadas com as entrevistas, podemos observar que o contrabando de agrotóxicos entre as cidades fronteiriças pode ocorrer com o uso de caminhões, carros, motos, aviões e embarcações fluviais. No caso das cidades localizadas à margem do Rio Paraná e ao Lago de Itaipu, as mercadorias são apresentadas como parcialmente distribuídas localmente e outra parcela armazenada e distribuída para outras regiões produtoras de monoculturas, como Goiás, Mato Grosso e Bahia. Isso pode ocorrer por meio de transportadoras, ônibus intermunicipais e interestaduais, carros, aviões etc. Por meio da pesquisa de campo, também 
observamos a prática de venda dos agrotóxicos oriundos do Paraguai pela internet, (algo comum aos eletrônicos), como estratégias para lidar com as fiscalizações, ocorrendo, por vezes, sem transitar pelas mesmas regulamentações legais exigidas a outros vendedores físicos (RPC, 2020; AÇÃO PF, 2020; PORTAL GUAÍRA, 2018).

Estes fluxos de mercadorias são semelhantes aos identificados com o "descaminho" e/ou "contrabando" de eletrônicos e cigarros ao longo das pesquisas já realizadas (FIOROTTI, 2018), mas, possuindo as especificidades dos destinos das mercadorias conforme maior consumo e planejamento da redistribuição. Cabe lembrar que em meio às pesquisas de campo que realizamos sobre o transporte não regulamentado de mercadorias na fronteira Brasil-Paraguai, há interlocutores que mencionam como "grande contrabando" os fluxos realizados em grandes escalas que carecem de grande investimento de capitais em sua logística, fazendo uso de meios de transportes que não possuem paradas e armazenamentos em pequenas cidades fronteiriças.

Para realização da circulação do agrotóxico entre a fronteira ParaguaiBrasil, fazem-se necessários não somente o capital investido indiretamente ou diretamente por grandes produtores rurais na existência e manutenção desse circuito. Também são mobilizados diversos trabalhadores, desenvolvendo diferentes estratégias e funções para que o produto chegue aos consumidores. Contudo, há menos trabalhadores mobilizados nessas tarefas, quando comparado ao contrabando de cigarros e ao descaminho de eletrônicos. O agrotóxico se trata de uma mercadoria destinada a um público consumidor específico, proprietário de terras ou com possibilidade de arrendá-las, condição essa vivida por poucos. Além disso, compreendemos que, quando esta prática envolve maiores movimentações de capital e distribuição da mercadoria para outras regiões do país, há maior controle da circulação e venda dos produtos por parte daqueles que são envolvidos e há uma quantidade de grupos restritos com influência nesse mercado (FIOROTTI; CARDIN; COLOGNESE, 2020).

Em maio de 2015, foi realizada uma longa entrevista em Guaíra com Zé Maria, que na época tinha 34 anos. Como "atravessador" ou popularmente 
conhecido por "patrão", ele coordenava um dos grupos envolvidos no "contrabando de cigarro" e contratava adolescentes para as tarefas necessárias a realizar a travessia na fronteira. Houve épocas que ele chegou a contratar cerca de 25 pessoas, mas no momento da entrevista havia reduzido para um terço essa proporção. A entrevista só foi possível porque o conhecia desde a infância e ele era amigo do meu irmão que, havia convivido com ele e compartilhado diversas partidas de futebol num campinho em um bairro resultante de um conjunto habitacional, BNH3. Zé Maria, assim como muitos amigos da minha infância naquele bairro, experimentou o envolvimento nas práticas consideradas "ilegais".

Ao longo de sua entrevista ele foi descrevendo comportamentos e posturas presentes em seu trabalho, indicando a existência de códigos morais e éticos desenvolvidos naquele ambiente. Entre eles, estava a confiança sobre a garantia da mercadoria que saia e chegava ao lado brasileiro envolta em embalagens de papelão e cobertas com sacos plásticos escuros, seria realmente a encomendada e não outras mercadorias que poderiam gerar penas mais pesadas em caso de apreensões. As relações de confianças também eram estendidas ao uso dos portos localizados em propriedades rurais, sendo alguns portos destinados a cigarros, eletrônicos, bebidas etc. e outros portos para contrabando de armas e drogas. Para ele, a própria patrulha da polícia na época da entrevista contribuía para garantir que os portos não fossem usados para tráfico de armas e drogas, despertando maior controle por parte da Polícia Federal sob o trabalho com os cigarros e eletrônicos.

Havia portos específicos para "coisas grandes" para "quem é rico”. Contudo, nesses últimos, também existiam transportes diferenciados, como o aéreo. Entre as "coisas grandes" relatadas na entrevista, ele também mencionou sobre o "veneno", que envolvia muito dinheiro, corrupção a agentes dos Estados brasileiros e paraguaios, que, uma vez entrando em "coisa grande

\footnotetext{
${ }^{5}$ Por meio da pesquisa de campo, observamos que o termo patrão, é amplamente utilizado para diferentes situações, sendo comum que se tenha alguém inferior a ele na hierarquia. Por exemplo, até mesmo um laranja pode ser assim referenciado, desde que ele terceirize seu serviço.
} 
e polícia, não dá para sair. Imagine o cara começar a querer dar prejuízo, aí vão querer fazer alguma coisa contra ele”. 6

Em sua entrevista, Zé Maria fazia questão de enfatizar o não envolvimento com o tráfico de armas e drogas. A interpretação e avaliação sobre seu trabalho baseava-se tanto nos seus costumes e valores e na forma como lidava em seu cotidiano com os limites entre o socialmente aceito ou não pela população local (FIOROTTI, 2015). Durante nossa conversa, ele fez planos sobre o tempo que permaneceria nessa prática e nos relatou sobre os investimentos que estava fazendo para abrir uma empresa de hospedagem para sair do "contrabando". Zé Maria planejava ter mais tempo para família e sonhava ter filhos. Sonhos esses que precisariam ser adiados, porque com a alta do dólar, ele precisaria ficar mais tempo que o planejado.

Zé Maria iniciou no trabalho por volta dos 10 anos de idade como auxiliar de mecânico em uma oficina do cunhado. Quando jovem, abriu sua própria oficina mecânica e borracharia em Guaíra. Um estabelecimento pequeno que, após alguns anos, não foi possível manter sem prejuízos. Mudouse para cidade de Lucas do Rio Verde no Mato Grosso, acompanhando a esposa na assunção de uma vaga no serviço público educacional. Ele alugou um estabelecimento para iniciar outra oficina mecânica, chegando a contratar três funcionários. Após alguns anos, o casal reavaliou as condições de vida experimentadas naquele lugar e a necessidade de estarem mais próximos da família de ambos, o que possibilitou o retorno a Guaíra e a abertura de outra borracharia. Aos poucos, com seu envolvimento na travessia de pneus oriundos do Paraguai, sentiu-se "empurrado" ou "motivado pelos amigos" a trabalhar com os cigarros. Durante a entrevista ele fez questão de enfatizar os esforços de sua parte para manter-se com a profissão de mecânico, sendo seu envolvimento descrito quase como conduzidos pelas suas relações sociais, condições socioeconômicas e culturais do lugar onde viveu e trabalhou (FIOROTTI, 2015).

\footnotetext{
${ }^{6}$ Zé Maria, 35 anos, nacionalidade brasileira. Entrevista feita por Cíntia Fiorotti Lima e Eric G. Cardin, em maio de 2015.
} 
O final de Zé Maria parecia previsto em sua entrevista realizada em 2015. No dia 16 de janeiro de 2017 o jornal de circulação no Mato Grosso, Expresso MT, anunciava que um homem entre 30 e 40 anos fora encontrado morto em uma plantação de soja, numa fazenda entre as cidades de Lucas do Rio Verde e Nova Mutum. Ele foi morto com um tiro na cabeça. O jornal anunciava a necessidade de reconhecimento da vítima para não ser enterrado como indigente. Uma moradora de Guaíra entrou em contato com o periódico no dia seguinte, "afirmou ser amiga da família e contou que Zé Maria trabalhava com vendas de agrotóxicos para as lavouras do norte de Mato Grosso, passando uma quinzena em Lucas e região e outra quinzena na cidade de Guaíra, junto dos familiares". 7

Provavelmente, Zé Maria entrou num circuito de circulação de capitais e mercadorias com um rígido controle dos lucros, envolvendo pessoas de uma classe social distante da dele. No chamado "contrabando de agrotóxicos" em grande quantidade, ou envolvendo as chamadas "quadrilhas" anunciadas pelas operações policiais, sempre emergem nas notícias de jornais e nas sentenças judiciais a criminalização de sujeitos que parecem repetir, em sua maioria, a mesma classe social. Normalmente, costumam ser expostos os nomes dos sujeitos envolvidos no transporte, no armazenamento e na distribuição destas mercadorias. Entre esses, alguns conhecidos como batedores de estradas, pilotos, bandeirinhas e formigas. O que não observamos emergir são os nomes dos consumidores, ou seja, dos proprietários de terras ou de empresas de agronegócios envolvidos no processo de produção e uso.

Os estudos dos geógrafos Adriana Dorfman, Arthur Borba Colen, Guilherme de Oliveira Soares (2014), ao trazerem a reflexão sobre o contrabando de agrotóxicos na fronteira Brasil - Uruguai, identificam a existência de pelo menos dois tipos de contrabando de agrotóxicos na região por eles estudadas. Um, desenvolvido por "passadores organizados", envolvendo uma escala maior de investimento e organização, tal como

\footnotetext{
${ }^{7}$ Expresso Mato Grosso. O link não foi disponibilizado porque visamos preservar o nome e identidade do entrevistado.
} 
caminhões e toda uma logística do transporte ilegal para abastecer o uso de agrotóxicos em outros estados brasileiros como, Paraná, Mato Grosso do Sul e Goiás. Outro, seria o contrabando considerado mais tradicional, envolvendo produtores rurais locais que realizam eles próprios a travessia para utilizarem nas lavouras de monocultura do trigo, arroz e soja.

Sobre o contrabando considerado mais tradicional apontado pelos autores ou o contrabando de pequeno porte, para uso nas próprias terras ou em terras arrendadas para produção de soja, identificamos nas entrevistas algumas formas de aquisição dos agrotóxicos oriundos do Paraguai. Primeiro, o transporte realizado pelos próprios produtores, quando os agrotóxicos são para uso em pequenas proporções ou em menor frequência, ocorre nas regiões e áreas onde há maior proximidade com a fronteira entre municípios paraguaios e brasileiros. A travessia costuma ocorrer por via terrestre e/ou por via fluvial pelo transporte em balsas, onde são os pequenos produtores rurais que realizam por conta própria o transporte dentro de seus carros ou utilizando motos.

Enquanto isso, os pequenos proprietários com terras um pouco mais distantes dos limites territoriais fronteiriços ou com dificuldade de chegar até as vias de transporte entre a fronteira, e/ou mesmo, aqueles que fazem usos de agrotóxicos em maiores proporções e com maior frequência, recorrem adquirilos ou encomendá-los aos sujeitos que eles conhecem e realizam a prática de atravessar o agrotóxico. Como também há aqueles que temem as implicações legais do transporte e, por isso, solicitam por outros meios. Por exemplo, em alguns casos relatados, há proprietários de agropecuárias que conseguem ou intermedeiam a compra dos agrotóxicos encontrados somente no Paraguai para seus clientes mais antigos utilizarem em suas plantações no Brasil.

Os pequenos proprietários rurais e 0 uso de agrotóxicos "contrabandeados"

As entrevistas realizadas indicaram a prática da compra de "veneno em pó" no Paraguai por parte de produtores rurais com terras no Brasil ou com terras em ambos os países, ao menos desde o final da década de 1960. Para uma 
parcela da população, essa prática era e continua sendo socialmente aceita entre a maioria dos produtores rurais na região. Vavá, 46 anos, natural da área rural de Foz do Iguaçu, argumentou o uso:

É bem mais barato, bem mais forte e funciona bem, bem melhor. Metade do preço. Sem imposto. Se for comprar aqui, sai caro pra gente. E sempre tem uns rapazes por aí que trazem. Só que tem que cuidar, não dá para pegar de qualquer um. Vai que o cara te vende farinha. [...]

Aqui no Brasil você compra de litro, de galão de 5 litros, de 10 ou 20 litros. A maioria usa de 20 litros porque tem plantadeira. No Paraguai, a maioria é em pó. Um pequeninho desses, em um pacotinho de um quilo, por exemplo, você tem que comprar aqui um galão de 20 litros. Você paga $\mathrm{R} \$$ 160,00 nesse e num galão do brasileiro vai uns $\mathrm{R} \$ 600,00$. No Brasil não tem esse em pó. E não é desse. [...] No Brasil não é liberado. A Acerola tá trazendo, a Acerola tem a fábrica no Paraguai. Ela traz um similar. Ela importa. Mas o preço já muda um pouco, fica parecido com o daqui, mas funciona. Esse que a LAR tem aqui, esse não tá funcionando mais.

Há tempos passava com aquele motorzinho ainda na soja alta, o LVC, caia no meio da soja com veneno. Esse último que a gente usou nem sei o nome, vem com uns nomes estranhos, é tudo chinês. Só usa para aquilo, para o percevejo marrom. ${ }^{8}$

Vavá é filho de produtores rurais que migraram do Rio Grande do Sul com a compra de terras no Paraná na década de 1960. Na década de 1970, a família de Vavá estava entre os primeiros reassentamentos iniciados com as indenizações realizadas pela Itaipu no processo de formação do Parque Nacional do Iguaçu. A maioria dos seus vizinhos eram da cidade de Santa Rosa, no Rio Grande do Sul, nome dado à região entre os reassentados, acrescido do nome indígena do Rio Ocoí. Hoje, Vavá trabalha nas terras que, após o falecimento do pai, ainda estão em nome de sua mãe. Reside junto a esposa e duas filhas na casa do sogro. Também trabalha na produção agrícola em conjunto ao sogro e mais um vizinho. Eles cuidam de todo processo envolvendo os cultivos das monoculturas de soja e milho. No caso de Vavá, ele não contrata

\footnotetext{
${ }^{8}$ Vavá, 46 anos, nacionalidade brasileira. Entrevista feita por Cíntia Fiorotti Lima e Oberty Coronel, em abril de 2018 em Santa Rosa do Ocoí no município de São Miguel do Iguaçu. A duração da gravação foi de uma hora e seis minutos, depois continua sem o registro do áudio.
} 
força de trabalho para a produção no campo. Ele é quem trabalha, fazendo uso de um trator simples na aplicação dos "venenos", no plantio e colheita.

A legitimidade aos usos dos agrotóxicos trazidos do Paraguai, ou como expresso em suas falas, "o veneno", consiste principalmente em enfatizar o lugar de onde fala. Como pequeno produtor rural, Vavá percebe sua condição de vida e trabalho no campo como diferente daqueles com maiores poderes aquisitivos. Ele depende das relações de confiança que estabelece com os atravessadores, precisando esses últimos fazer parte ou serem indicados por alguém de suas redes de relações. Utiliza os serviços de um trabalhador envolvido no transporte não regulamentado e/ou ilegal de mercadorias entre o Paraguai e o Brasil, diferentemente de quem tem poder aquisitivo de compra e pode vir a conseguir algo similar e forçosamente "regulamentado" para aplicar em suas lavouras, consumindo de uma das agropecuárias com sede no Brasil e no Paraguai.

No caso dos "venenos do Paraguai", esses foram relatados por ele como usados em menor frequência, a cada um ou dois anos, quando o percevejo marrom danifica as lavouras em grandes proporções. Essa pressão e "autocontrole" em cuidar a quantidade de agrotóxicos a serem consumidos do Paraguai emerge na possibilidade de precisar acionar o seguro, em caso de perdas significativas das lavouras. Essa ação necessitaria da comprovação de notas fiscais de compras de agrotóxicos no Brasil, indicados por técnicos agrícolas nos cultivos de soja e milho.

Durante a pesquisa de campo, em outra conversa, nota-se que alguns produtores rurais que também fazem uso de agrotóxicos contrabandeados acionam o seguro quando não conseguem atingir o almejado ao final da produção. Para isso, costumam subornar o perito para notificarem as perdas na lavoura, vendendo a produção que atingiram e recebendo a indenização garantida pelo seguro. Essa prática é rejeitada por muitos produtores, que preferem seguir na monocultura, selecionando entre as práticas ilegais aquilo que julgam moralmente como aceito pelas suas culturas e pelos costumes locais. 
No caso de Vavá, desprovido de maquinários de altos valores e de poder aquisitivo de compra, ele também não consegue adquirir "venenos" regularizados em território nacional com efeitos mais potentes, porque carecem a comprovação da posse de trator com cabine para aplicação. Contudo, muitos costumam passar secantes ou agrotóxicos durante a noite, para que ninguém veja que não estão utilizando os maquinários exigidos. Eles não conseguem alugar esses maquinários com a frequência que seria necessário. Mesmo cientes sobre o risco da contaminação, ponderam os riscos mais aceitáveis que as possíveis consequências das perdas, caso não façam uso desses produtos.

Sr. Dedé, o sogro de Vavá, visando acompanhar a produção voltada para o agronegócio, perdeu parte de suas terras devido ao endividamento com o banco, ocasionado pela compra de maquinário agrícola e pelos juros abusivos. Muitos desses pequenos proprietários são estimulados ao endividamento, acreditando na possibilidade de também trabalharem com os maquinários como contratados em outras terras, "nós fomos três anos colher no Paraguai, não conseguimos mais pagar a máquina, e o juros foi lá em cima, e deu no que deu. Até hoje estamos com divida da época (1983). Pelo menos hoje não aparece mais oficial de justiça". ${ }^{9}$

Sr. Dedé, 67 anos, é um dos pequenos proprietários rurais entrevistados em Santa Rosa do Ocoí na cidade de São Miguel do Iguaçu. Ele mora na propriedade com a esposa, o genro Vavá, sua filha e duas netas. Dos três filhos que teve, dois saíram do campo e exercem outras profissões. Nascido no interior do Estado de Santa Catarina, acompanhou a família na migração para o Paraná em 1961, tendo o pai comprado terras na região onde hoje é delimitada como Parque Nacional do Iguaçu. Seu pai migrou em busca de terras mais férteis. Com o processo de formação do Parque Nacional do Iguaçu, sua família também vivenciou um dos primeiros reassentamentos iniciados em 1974. Ele e seu irmão ocuparam parte das novas terras do pai, divididas entre os irmãos, tendo eles recebido 10 hectares.

\footnotetext{
${ }^{9}$ Dedé, 67 anos, nacionalidade brasileira. Entrevista feita por Cíntia Fiorotti Lima e Oberty Coronel, em abril de 2018 em Santa Rosa do Ocoí no município de São Miguel do Iguaçu. A duração da gravação foi de uma hora e seis minutos, depois continua sem o registro do áudio.
} 
Quando eu tinha uns 16 ou 17 anos, plantava um milho e quando o milho estava dessa alturinha, plantava mandioca, batata doce. Cada dois carreiros de mandioca, plantava um de milho, depois a cada dois, um de feijão. Plantava soja separado. E mandioca, plantava mandioca num metro e depois que a mandioca era de dois anos, plantava uma abóbora no meio para fazer aquela lavagem, aquela comida que usava para tratar os porcos. Criava muito porco. Cada sessenta dias, matava 8 a 10 porcos. Na época não usava veneno, mas as vezes, usava um pouquinho de veneno em pó. Veneno só depois que o pessoal começou a plantar soja e milho, aí as pragas apareceram mais. Até 80 por aí que começou depois para passar veneno. A cooperativa já tinha quando viemos. Já tinha sede, lá na sede do INCRA, já começou. A LAR entrou por ali. O Manfred, era o nosso primeiro técnico, gerente que atendia a gente.

A cooperativa LAR, iniciada em 1964, se estabelece na região tentando organizar as monoculturas de soja e milho, dando assistência técnica aos produtores, orientando os financiamentos, vendendo sementes, adubos, agrotóxicos e outras mercadorias destinadas à nova lógica de produção mecanizada de monoculturas. $\mathrm{O}$ processo de reorganização da produção rural também contou com os impactos decorrentes do reassentamento após a formação do Parque Nacional de Itaipu. Junto ao projeto "modernizador", expresso na presença da construção da hidroelétrica de Itaipu na década de 1970 na região Oeste do Paraná, estava principalmente a expansão do agronegócio. Os pequenos produtores rurais, ainda organizados em uma agricultura voltada para subsistência, chegavam às novas terras carregando algum dinheiro das indenizações e logo já eram cooptados para inserirem-se dentro do mercado voltado para monoculturas. Tal processo proporcionou violentas mudanças nos modos de vidas daqueles trabalhadores rurais. ${ }^{10}$

Quando viajamos para realizar as entrevistas na propriedade do Sr. Dedé, havia recém identificado a minha gestação. Me lembro que enquanto

\footnotetext{
${ }^{10}$ A associação entre a construção da usina e o processo de modernização da região, tema da dissertação de Catta (1999), trouxe consequências que a própria hidrelétrica precisou reconhecer como negativas. Em ação movida pela Colônia de Pescadores de Guaíra, Itaipu reconhece que a diminuição do número de peixes no lago está diretamente relacionada ao modelo de exploração agrária existente na região, responsável pelo processo de contaminação das águas e a consequente diminuição das espécies existentes. Sobre o assunto, ver a Ação Civil Pública $\mathrm{n}^{\circ}$ 5061732-69.2015.404.7000 e a Produção Antecipada de Provas $\mathrm{n}^{\circ}$ 506173184.2015.404.7000.
} 
andávamos nas estradas rurais e passávamos por muitas plantações de soja, eu me recordava das orientações da médica obstetra: "agora, nas primeiras semanas de gestação, não deve frequentar áreas com plantio de soja e milho devido ao número de bebês nascidos com fenda palatina na nossa região”. ${ }^{11}$ Não havia quase nenhuma árvore na estrada, não havia plantas frutíferas e, de muito longe, se enxergava uma pequena área verde destinada a uma reserva indígena.

Ao chegarmos à casa do Sr. Dedé e de Vavá, eles não estavam. A residência deles não possuía muitas árvores ao redor, era simples, mas espaçosa e aconchegante, havia um jardim muito bem cuidado onde fomos convidados para sentar-se. Fomos calorosamente recebidos pelas suas famílias, com chimarrão e bolachas caseiras, e conversamos muito, sem o uso do gravador, com as mulheres e com o cunhado do pesquisador (filho do Sr. Dedé), que nos levou até lá. Tais condições favoreceram muito o momento da entrevista. Ali havia três gerações de mulheres, a mãe, a filha e a neta. A mãe, aposentada como trabalhadora rural, continuava a trabalhar em casa, cultivava a horta e criava porco, vaca e ovelha. A filha era professora e se deslocava todos os dias para o trabalho na escola mais próxima a sua casa, ajudando a mãe com o trabalho na criação de animais. A neta era estudante de antropologia na UNILA e, também, se deslocava todos os dias para estudar. Essa mencionou que queria permanecer no campo.

Sr. Dedé e Vavá chegaram bem tarde do trabalho. Estavam colhendo. Diferentemente de Vavá, Sr. Dedé fez questão de trazer em suas falas como era viver e trabalhar antes das mudanças proporcionadas com a mecanização do campo e os cultivos de soja e milho. Falou sobre as diversidades de cultivos, como eram organizados e lamentou não conseguir mais ter pomar em suas terras, devido aos impactos causados pelo secante ou venenos utilizados ao

${ }^{11}$ Somam-se a estas informações as pesquisas na área da saúde, como a pesquisa de Lidiane Silva Dutra e Aldo Pacheco Ferreira (2017) que, em um artigo intitulado "Associação entre malformações congênitas e a utilização de agrotóxicos em monoculturas no Paraná, Brasil", estabelecem a relação entre o uso de agrotóxico e a malformação congênita identificada em recém-nascidos em algumas cidades como Cascavel, Toledo e Francisco Beltrão. Entre as malformações são observadas, por exemplo, fenda labial e problemas nos sistemas neurológicos, respiratório e reprodutores. 
redor nas lavouras. Ele também comentou, um pouco ressentido, que havia um vizinho seu que conseguia manter um pequeno pomar, mas que para isso “deixava uma área grande de quiçaça perto para os bichos irem para lá”. No caso dele, isto não era avaliado como possível. Para ele, como para sua esposa, viver e trabalhar no campo era uma luta pela sobrevivência e permanência em um espaço onde se formaram e constituíram suas vidas. Contudo, sentia o impacto das mudanças no campo em suas vivências. Isso também emergiu quando fez referências às soluções encontradas para as dívidas cobradas judicialmente por um dos bancos "Graças a Deus ainda temos para comer. Agora eu já consigo financiamento".

Outro marco importante de mudanças sentidas pelo Sr. Dedé foi a introdução do plantio direto. Para ele, esse método aumentou o uso de "veneno" e o número de pragas resistentes existentes nas lavouras. Sobre as mudanças vividas, Sr. Dedé e Vavá disseram

Que nem hoje, tem veneno para folha estreita, para folha larga, antigamente o que tinha era para folha estreita. $\mathrm{Na}$ época, lavrava tudo, não fazia o plantio direto que nem hoje, deixava a terra bem soltinha. Lavrava ou passava um pé de pato e daí uns dias antes de plantar passava um herbicida por cima para controlar a semente da folha estreita, mas para folha larga não tinha. Eu sei que era a Triflorina, essa incorporava a terra. Passava com o pulverizador e depois passava a grade. Conforme você passava e dava torrão, aí para você deixar a terra mais solta, tinha que passar duas vezes a grade. Só que naquela época o diesel era bom, só que gastava muito combustível. Acho que faz uns vinte anos atrás que começou o plantio direto, em 1994. Teve um agrônomo que veio esses tempos aqui e quis começar a voltar a mexer a terra e quem mexeu colheu menos. Teve 7 hectares que ele mexeu e 7 que ele não mexeu, e onde mexeu deu dez sacos a menos. Na verdade, só soltaram um pouco. Antes era mais trabalheira, e os tratorzinho pequeno. Rs. Hoje é mais fácil, porque até mosquito você mata com veneno. VAVÁ: O marco mesmo é quando se começou a usar o plantio direto, não se tombava mais. Num dia colhi e no mesmo dia foi deixado pronto o plantio.

E vocês se vêm obrigados a usar os venenos?

SR. DEDÉ: Sim, se não, não produz.

VAVÁ: outros tipos de concentrações, porque aqueles venenos estão ficando muito fraco e o percevejo mais resistente. É quase uma vez por semana quase. Tem que ficar 
monitorando. No milho você passa duas ou três vezes com fungicida, mas no feijão, tem que ser duas vezes por semana. A soja é uma vez por semana. Tudo depende do clima também ${ }^{12}$.

A forma como Sr. Dedé procura descrever detalhadamente as etapas e o trabalho despendido no cuidado na preparação da terra expressam parte dos significados da sua relação com o trabalho rural. Para ele, o plantio direto trouxe uma outra organização do tempo. Após as colheitas, não se espera mais a recuperação da terra e nem do trabalhador. Ainda, os conhecimentos em torno dos tipos de insetos e doenças que atacavam as lavouras também já não eram mais os mesmos que o Sr. Dedé possuía. Voltar à produção anterior, em que ele detinha maior controle e conhecimento, significaria não produzir o suficiente para arcar com suas expensas e ter os ganhos necessários para se manter no campo.

A intensificação da produção agrícola e as inovações tecnológicas não significaram melhoras na qualidade de vida desses trabalhadores. A pressão sofrida pelos pequenos proprietários rurais com o agronegócio estendeu-se para sua vida familiar. Há menos espaço e condições ambientais para família cultivar produtos para seu próprio consumo. Ainda, o marco de mudança destacado pelo Sr. Dedé coincide com o período em que também perdeu seu irmão. Aquele que iniciou junto a ele a autonomia como pequenos proprietários e produtores rurais no reassentamento de Santa Rosa do Ocoí em 1974. Sua família nos relatou que, após dias de intensa aplicação de veneno em suas lavouras, ele viajou para o Mato Grosso e faleceu. O laudo médico foi de malária, mas a família suspeita do uso intenso de veneno em lavouras dias antes de sua viagem.

\section{Os pequenos produtores rurais e a resistência ao uso de agrotóxicos}

Nas entrevistas com os pequenos produtores orgânicos e/ou agroecológicos, realizadas nas cidades de Toledo, Entre Rios e Pato Bragado no Paraná, observa-se que o início da produção sem o uso de agrotóxicos

\footnotetext{
${ }^{12}$ Sr. Dedé e Vavá. Entrevista gravada em São Miguel do Iguaçu em abril de 2018.
} 
combinou vários fatores motivadores. Embora cada um possua seu peso e significado, elencamos alguns desses motivos: a oferta de cursos da EMATER; o adoecimento pelo contato com os "venenos"; os altos custos necessários para manutenção na chamada "produção convencional" de monoculturas; a dificuldade de manutenção no campo com qualidade de vida.

As referências à saúde para reforçarem as necessidades das mudanças na forma como os pequenos produtores rurais organizavam sua vida e trabalho no campo foram elementos fortemente marcados ao longo das entrevistas. O processo de conversão ou transição parece ter implicado em mudanças nas percepções sobre o uso da terra e a vida no campo. Muitos dos sujeitos entrevistados fizeram questão de trazer em suas falas exemplos de pessoas da família ou deles próprios acometidos de doenças, pressupondo os desencadeamentos das mesmas pelo uso de agrotóxicos. Entre eles, os produtores rurais Lírio, de 52 anos, e, Begônia, de 48 anos, ambos naturais do Rio Grande do Sul, mencionaram, “a gente teimou (em produzir orgânicos) mais por causa da saúde mesmo, porque eu ia nas vacas e passava carrapaticida e ficava tonto, ficava ruim, eu já tinha problema no fígado, foi por saúde mesmo." 13

A teimosia expressa na fala de Lírio, relaciona-se, entre outros motivos, às dificuldades enfrentadas para manutenção no campo durante o chamado processo de conversão. Essa implica nas mudanças graduais da produção agrícola "convencional" para a orgânica. O controle de pragas nas terras produzidas, assim como, a preparação do solo demora certo tempo. Segundo o agricultor, "não tem como fazer tudo de uma vez, é aos poucos mesmo porque se não quebra. Tem que ir desintoxicando o solo. No primeiro ano fui plantando feijão. Eu certifiquei por partes [...]". ${ }^{14}$

\footnotetext{
${ }^{13}$ Lírio, 52 anos e Begônia, 48 anos, nacionalidade brasileira, produtores rurais em Toledo com certificação de produção "orgânica". Entrevista gravada em julho de 2018. A duração da gravação foi de uma hora e vinte minutos, depois continua sem o registro do áudio. Estavam presentes na entrevista os pesquisadores: Sandra C. Kleinschmitt, Cíntia Fiorotti Lima e Eric G. Cardin. A transcrição da fonte foi ajustada visando contribuir com a leitura.

${ }^{14}$ Lírio e Begônia. Entrevista gravada em Toledo em julho de 2018.
} 
A conversão implica toda uma mudança na forma de organização da produção, exigindo novos conhecimentos no manejo e cuidado com os alimentos, a terra e os animais. Cursos, como os de elaboração e aplicação de homeopatia em seres vivos, são ofertados a esses produtores por instituições em parcerias. Da mesma forma, ocorrem mudanças nas rotinas e na relação com o tempo de trabalho. Há um longo e demorado processo de reorganização do trabalho e da vida no campo, marcado por muitas dificuldades. A maioria dos entrevistados sinaliza as dificuldades econômicas encontradas no início do processo de transição, já que a produção orgânica exige saberes diferentes daqueles adotados na produção convencional.

Um elemento importante nas falas dos entrevistados é perceber como a terra emerge como um meio importante de sobrevivência e manutenção na área rural. Em meio a relações sociais capitalistas de produção, a terra é onde o pequeno produtor rural necessita trabalhar e fazer sua renda. Antes da conversão de hábitos alimentares e de consumo, também há o peso da necessidade de manutenção no campo com o trabalho na terra.

$\mathrm{Na}$ teimosia, ainda estão as dificuldades de manter as "barreiras vegetadas". Essas estão entre os critérios de reconhecimento e manutenção da produção de orgânicos. De maneira superficial, trata-se do plantio e manutenção de certos tipos específicos de plantas diversificadas para formação de "barreiras vegetadas", visando a contenção do contato com agrotóxicos utilizados nas propriedades vizinhas. São nos danos a essas barreiras que os impactos do uso de determinados agrotóxicos nas propriedades aos seus redores são visualizados mais diretamente pelos produtores orgânicos.

As chamadas "barreiras vegetadas" diferenciam os produtores orgânicos dos demais produtores, sendo comum conflitos em torno de sua manutenção entre produtores orgânicos e convencionais. Elas marcam a fronteira entre concepções diferentes na forma de organizar a vida e o trabalho no campo. Conforme Lírio e Begônia relataram, “o que a gente já brigou com o vizinho aqui do lado que ele mata a minha barreira. Tem que ser persistente. Aí ele 
reclama que as canas caem na propriedade dele e quebra a corrente da colheitadeira dele. Eles não gostam, mas a gente também não gosta." ${ }^{15}$

$\mathrm{O}$ envolvimento desses pequenos proprietários com os cultivos orgânicos ou agroecológicos expõem uma concepção de trabalho e vida no campo diferente da predominante nessa região. Eles trabalham com suas famílias na terra e consomem seus próprios alimentos. Em sua maioria, são poucos os que conseguem contratar mão de obra para auxiliar na criação de animais e na manutenção dos cultivos, não havendo uso de maquinários convencionais. A relação entre o produtor e a terra passa por mudanças conforme o sujeito começa a ter novas percepções sobre a produção que é consumida e direcionada à comercialização com uma identificação diferenciada. Já o produtor rural "convencional" das monoculturas de soja e milho não costuma consumir alguns de seus produtos in natura. Para esses últimos, cada espaço da terra na propriedade é voltado para uma produção imediata e para o mercado agroexportador.

Nas entrevistas realizadas com os pequenos produtores rurais, há referências aos impactos do uso de determinados secantes e "venenos" aplicados nas lavouras vizinhas que atingem prejudicialmente parte de seus cultivos. Quando os entrevistados falavam sobre grandes perdas na produção orgânica em consequência ao uso de agrotóxico na produção convencional de soja e milho ao entorno de suas propriedades, faziam questão de mencionar que era comum o uso de agrotóxicos trazidos irregularmente do Paraguai e aplicados indiscriminadamente nas lavouras vizinhas. No caso do município de Toledo, as aplicações também acontecem pelo meio aéreo.

Lírio e Begônia possuem trajetórias similares as de Dedé e Vavá. São filhos de produtores rurais, tendo pais que viviam de uma produção agrícola diversificada em pequenas cidades no norte do Estado do Rio Grande do Sul. A migração dos pais para o Paraná veio com a expectativa da compra de uma extensão maior de terras produtivas em relação àquelas que possuíam em seus locais de origem. Eles acompanharam os pais na migração quando ainda eram

\footnotetext{
${ }^{15}$ Lírio e Begônia. Entrevista gravada em Toledo em julho de 2018.
} 
crianças, fixando-se incialmente na área rural de Novo Sobradinho, distrito de Toledo-PR. O pai de Lírio iniciou a produção de soja, trigo e milho durante a década de 1970. Pouco tempo depois ele faleceu.

Conforme Lírio e Begônia, quando eles se casaram e foram morar na propriedade de 7.2 hectares, mantiveram cultivos alternados, tendo a soja plantada até praticamente a porta da casa e a vendendo para as cooperativas agrícolas. Entre os irmãos, que também receberam parte da partilha das terras, eles são os únicos que permaneceram no campo. Para o casal, a mudança para a produção orgânica decorreu entre outros motivos, porque "não havia mais como sobreviver de soja com pequena propriedade". Os investimentos e a necessidade de financiamentos para manutenção da produção e aluguel dos maquinários comprometia boa parte da renda obtida.

O processo de mudanças nos modos de vida e organização do trabalho no campo vivenciado por Lírio e Begônia foram marcados ao menos por dois momentos. Primeiro, ainda na infância, acompanharam junto aos pais o processo de migração e as mudanças na concepção de produção no campo, passando dos cultivos diversificados, ainda em terras no norte do Rio Grande do Sul, para a monocultura combinada à mecanização do campo em terras no Oeste paranaense. Segundo, após a longos anos envolvidos com o que predominou popularmente na região como "agricultura convencional", viveram o processo de transição para o cultivo diversificado na terra sem a utilização de agrotóxicos. Como mencionaram, "nunca vi, nunca ouvi" sobre "barreiras vegetadas" antes do incentivo à produção orgânica.

Para além das dificuldades de manutenção no campo com os cultivos da soja e milho, houve outros fatores impulsionando essa mudança. Conforme os entrevistados, o interesse pela produção de orgânicos foi despertado por um curso oferecido pelo Sindicato dos Trabalhadores Rurais no começo do século XXI. O curso iniciou com aproximadamente quarenta participantes e terminou com apenas seis. Os concluintes fundaram a associação dos produtores de orgânicos de Toledo no mesmo ano, objetivando regulamentar e proporcionar a comercialização de produtos agroecológicos. 
Camélia e sua mãe, Dália, pequenas produtoras rurais de orgânicos, também fizeram uso de alguns dos conhecimentos adquiridos com os cursos da EMATER e do auxílio de outros produtores envolvidos com a Associação dos Produtores Orgânicos de Toledo-PROORTO, com o Centro de Apoio a Promoção da Agroecologia-CAPA, vinculada à Rede ECOVIDA, o que lhes possibilita a certificação da produção. Os conhecimentos para produção orgânica partiram principalmente de Dália. Com 75 anos, natural de Rodeio Bonito, Rio Grande do Sul, possuía experiência com cultivos diversificados de grãos e hortaliças e com a criação de animais. Ela e o esposo iniciaram com 5 alqueires no cultivo de trigo, soja, milho e a suinocultura para os frigoríficos locais em 1970. Por volta de 1982, montaram os aviários em parceria com a BRF, após as mudanças nas exigências de adequação e acordos estabelecidos pela empresa, tentaram se manter por mais alguns anos com a avicultura, mas desistiram com o tempo, ao avaliar que não era mais compensatório.

Em meio a esse processo, as terras de seus pais foram vendidas para a construção do Biopark, o que permitiu a realização de investimentos que garantiram a sobrevivência durante o processo de conversão/transição. Como mencionou Camélia, "apareceu o projeto do Biopark, estávamos dentro da área pretendida por eles, e duas situações, você não briga com cachorro grande, e a proposta também era irrecusável, essa bichinha aqui dizia que só ia sair de lá morta, foi impactante né, e então teve essa transição pra essa área aqui." "16 Assim que se mudaram, Camélia perdeu o esposo e vivenciou o adoecimento progressivo do pai causado pelo câncer no intestino. Doença relacionada, conforme a família, ao uso de "veneno". Ela e a mãe decidiram trabalhar com a produção rural de orgânicos e manter parte na "produção

\footnotetext{
${ }^{16}$ Camélia, 40 anos, natural de Toledo-PR e Dália, 75 anos, natural de Chapada-RS. Entrevista gravada em julho de 2018, na área rural do município de Toledo. A duração da gravação foi de duas horas, depois continua sem o registro do áudio. Estavam presentes na entrevista os pesquisadores: Sandra C. Kleinschmitt, Cíntia Fiorotti Lima e Eric G. Cardin. A transcrição da fonte foi ajustada visando contribuir com a leitura.
} 
convencional" com o arrendamento das terras ao cunhado, com medo de não conseguirem se manter. ${ }^{17}$

As pressões sofridas pelos pequenos produtores rurais sobre suas formas de organização da produção também são materializadas na venda de suas terras àqueles que possuem maior capital. As tentativas sistemáticas do que irão produzir e como produzir, relacionam-se diretamente na exploração do trabalho desses sujeitos. Quando perdem esse controle, criam mecanismos para dificultar a manutenção dos pequenos proprietários no campo. A falta de políticas públicas está entre as queixas comuns trazidas pelos pequenos produtores rurais.

As dificuldades elencadas pelos produtores para se manterem no campo com os cultivos de alimentos classificados por "orgânicos", voltados para a subsistência e o comércio, trazem parte das pressões e a luta cotidiana vivenciada por não aderirem a organização da produção controlada por monopólios envolvidos no agronegócio. São exemplos, os ataques às barreiras vegetadas e à comercialização dos produtos. Contudo, isso não implica dizer que a forma como esses trabalhadores organizam a produção e seus próprios modos de viver por meio do trabalho rural não estejam articuladas ao mercado na sociedade capitalista.

Muitos desses pequenos proprietários, ao procurarem se adequar às normas e exigências da "produção orgânica" ou atenderem as demandas da "produção agroecológica" para comercialização dos seus produtos, o fazem de maneira articulada às redes técnicas de apoio. Ao se tornarem membros de uma associação de produtores orgânicos e buscarem assistência técnica em projetos de extensão das universidades locais e de instituições sociais os produtores desejam facilitar a certificação e a comercialização dos cultivos. No entanto, os vínculos entre a produção orgânica e o capitalismo se estreitam quando se

${ }^{17}$ A formação do Biopark é realizada pela indústria farmacêutica Prati-Donaduzzi, localizada em Toledo-PR. Se apresenta como centro de "biotecnologia", com diversas estruturas, entre elas construções de espaços físicos visando abrigar algumas universidades. Trata-se de uma empresa com grande capital e apoio sistêmico de representantes políticos. A compra de terras para formação do Biopark, tem sido relatada por muitos dos pequenos produtores rurais, principalmente os que desenvolvem agricultura orgânica em seus entornos. Lírio e Begônia também relataram a pressão que sofrem para vender suas terras à empresa. 
observa a expansão do uso dos pacotes biológicos produzidos pelos laboratórios para substituir os pacotes químicos.

Enquanto produtora rural, formada em Nutrição, Camélia não quer “mandar comer veneno”. Para ela, trabalhar com os orgânicos também é uma escolha política. "Devíamos usar o que os nossos antepassados usavam. Comiam apenas o que produziam. Tudo bem que tem pessoas que não tem escolha, mas quem tem oportunidade deveria. Você sabe o que você está comendo". Camélia vivenciou uma mudança no modo de vida e no significado que atribui ao que seria qualidade de vida. A noção de tempo de trabalho pretendida por ela com a produção dos orgânicos objetiva respeitar seus tempos e o lazer: "Se seguir as regras do mercado ele não vai permitir. Nas minhas regras sim. Mas o mercado é muito exigente. Não posso seguir o ritmo que ele impõe". ${ }^{18}$

\section{Considerações finais}

O processo de mudança vivenciados por estes trabalhadores pode ser observado nas alterações nos modos de vida. Velhos saberes sobre a produção na terra são recuperados e outros descartados ou adaptados às novas exigências do "mercado dos orgânicos". Não se trata somente de produzir como os antepassados, mas de organizar a produção e sua rotatividade dentro de critérios pré-estabelecidos. Por isso, a produção agroecológica tem sido indicada por eles como uma alternativa a essas exigências.

O trabalhador rural envolvido com a produção de orgânicos está vulnerável nesse processo, tanto nas dificuldades de comercialização de uma produção diferenciada, quanto na sua manutenção no campo com uma organização da vida e do trabalho diferente da "imposta" pelas classes dominantes locais que incentivam a monocultura para exportação. Para a produção convencional das monoculturas de soja e milho, a produção "orgânica e/ou agroecológica" combinada às ações de instituições e políticas públicas para

\footnotetext{
${ }^{18}$ Camélia e Dália. Entrevista gravada em Toledo em julho de 2018.
} 
tentar manter os trabalhadores rurais e pequenos proprietários de terra no campo, são considerados uma "fronteira-barreira" para a expansão do agronegócio com monoculturas para exportação. Essa última percebe, na transformação dos pequenos proprietários rurais em produtores de soja e milho, a ampliação das áreas produzidas e dos consequentes lucros obtidos nesse setor da economia.

O uso dos agrotóxicos "contrabandeado" ou, como definem nossos interlocutores, o "veneno", faz-se presente nos processos de produção em suas pequenas propriedades como respostas às pressões sofridas com o agronegócio. Tais respostas buscam burlar parte das normas e critérios de controle da produção em território brasileiro. Os pequenos produtores e os trabalhadores rurais responsáveis pela aplicação direta ficam vulneráveis aos efeitos dos agrotóxicos, seja eles regulamentados ou não.

Os trabalhadores envolvidos no transporte e uso destas mercadorias possuem pouco poder aquisitivo, tendo sua força de trabalho explorada nesse circuito. Já o "contrabando" em grandes escalas envolve uma logística de caminhões e outros transportes, que requerem alto poder aquisitivo. Realidade muito próxima das experiências observadas com o contrabando de café nas décadas de 1960 na região Oeste do Paraná. Contudo, cada um com suas especificidades e impactos sociais diferentes.

As experiências de pequenos produtores ruais na reorganização da produção "orgânica e ou agroecológica" fossem em associações, cooperativas ou recebendo o suporte de instituições públicas ou não governamentais CAPA e a PROORTO tem contribuído com a manutenção e permanência desses trabalhadores no campo.

\section{Referências}

AÇÃO PF. Notícias. PF realiza apreensão de veículo com grande quantidade de agrotóxicos (Pato Bragado). Disponível em: < https://www.gov.br/pf/ptbr/assuntos/noticias/2020/03-noticias-de-marco-de-2020/pf-realiza-apreensao-deveiculo-com-grande-quantidade-de-agrotoxicos> Acesso em 20 de março de 2020. 
BOSI, Antônio (Org.). Catálogo da Coleção dos Autos Criminais da Comarca de Toledo (1954-1980). 1. ed. Cascavel: EDUNIOESTE, 2003.

CARDIN, Eric Gustavo. (2017). O Fazer-se Estado nas Fronteiras: um estudo das relações entre trabalhadores fronteiriços e agentes estatais nos limites do Brasil. In: Anais do VI Simpósio de Pesquisa Estado e Poder: Estado, Poder e Revoluções. M. C. Rondon: UNIOESTE.

CARMO, Samanta. Uol Congresso em foco. Ministério da Agricultura libera 31 novos agrotóxicos. Metade é considerada altamente tóxica. Disponível em: $<$ https://congressoemfoco.uol.com.br/especial/noticias/ministerio-daagricultura-libera-31-novos-agrotoxicos-lista-foi-publicada-no-diario-oficialda-uniao/>. Acesso em 20 de abril de 2019.

CATTA, Luiz Eduardo Pena. O cotidiano de uma fronteira, a perversidade da modernidade. Dissertação de mestrado em história. Florianópolis: UFSC, 1994.

DARC, Aparecida. (2009) Formação econômica e social de Foz do Iguaçu: um estudo sobre as memórias constitutivas da cidade (1970-2008). São Paulo: USP. Tese (Doutorado em história econômica).

DORFMAN, Adriana, FRANÇA, Arthur Borba Colen, SOARES, Guilherme de Oliveira. (2014). Marcos legais e redes de contrabando de agrotóxicos: análise escalar a partir da fronteira Brasil-Uruguai. En: Terra Plural, v. 8, n. 1. Ponta Grossa. Pp. 37-53.

Adriana, REKOWSKY, Carmen Janete. (2011) Geografia do contrabando de agrotóxicos na fronteira gaúcha. En: Anais do XIII Encuentro de Geógrafos de América Latina, Costa Rica.

FIOROTTI, Cíntia. (2015). História de trabalhadores e do trabalho na fronteira Brasil-Paraguai (1960 - 2015). Tese (Doutorado em História). UFU: Uberlândia.

O viver e o sobreviver da fronteira Paraguai-Brasil: mercado, nacionalidade e trabalhadores. Revista de Ciências Sociais (UFC)., v.49, p.63 92, 2018.

; CARDIN, E. G.; COLOGNESE, Silvio A. fronteiras da ilegalidade: a importação e o uso de agrotóxicos ilegais na fronteira do brasil com o paraguai. Revista GeoPantanal (UFMS), v.15, p.61 - 77, 2020.

;SILVA, R. M.; LEITE, V. J.; Experiências de pesquisa com fontes orais na história social: caminhos e possibilidades. História Oral, v.23, p.243 $258,2020$.

MENEZES, Alfredo da Mota. A herança de Stroessner: Brasil-Paraguai, 1955-1980. Campinas, SP: Papirus, 1987. 
MOREIRA, Matheus. Folha de S. Paulo. Número de agrotóxicos liberados no Brasil em 2019 é o maior dos últimos 14 anos. Disponível em: <https://www1.folha.uol.com.br/ambiente/2019/12/numero-de-agrotoxicosliberados-no-brasil-em-2019-e-o-maior-dos-ultimos-14-anos.shtml>. Acesso em 20 de abril de 2020.

OLIVEIRA, Cida. Rede Brasil Atual. Agrotóxicos: Pacote do Veneno avança no governo Bolsonaro. "Desde que Jair Bolsonaro e sua ministra tomaram posse, já foram liberados um total de 551". Estes números foram divulgados em 04 de março de 2020.2 Disponível em: $<$ https://www.redebrasilatual.com.br/ambiente/2020/03/agrotoxicosrebaixamento-grau-toxicidade/>. Acesso em 20 de março de 2020.

IDESF, Instituto de Desenvolvimento Econômico e Social de Fronteiras. O contrabando de defensivos agrícolas no Brasil. Foz do Iguaçu, 2019.

PORTAL GUAÍRA, Guaíra - Patrulha Rural apreende agrotóxicos em porto clandestino. (estavam embalados em papel laminado). Disponível em: $<$ https://www.portalguaira.com/guaira-patrulha-rural-apreende-agrotoxico-emporto-clandestino/>.

ROJAS VILLAGRA, Luis. Actores del agronegócio em Paraguay. Asunción: Diakonia; Base-is, 2009.

RPC Cascavel. G1 Globo. Motorista com 230 kg de agrotóxicos contrabandeados é preso após perseguição em Guaíra, diz PRF. Disponível em: <https://g1.globo.com/pr/oeste-sudoeste/noticia/2020/03/07/motorista-com230-kg-de-agrotoxicos-contrabandeados-e-preso-apos-perseguicao-em-guaira-dizprf-video.ghtml>. Acesso em 20 de março de 2020.

SENTENÇA PÚBLICA. Operação Quileros. Disponibilizada ao público em agosto de 2018.

Recebido em: 24 de junho de 2020

Aceito em: 04 de setembro de 2021 